\title{
Método alternativo e sustentável para a realização de coloração bacteriana de Gram e Wirtz-Conklin: Relevância ambiental e econômica no ensino prático da
}

\author{
microbiologia
}

\author{
Alternative and sustainable method for performing Gram and Wirtz-Conklin bacterial staining: \\ Environmental and economic relevance in practical microbiology teaching
}

Método alternativo y sostenible para realizar la tinción bacteriana Gram y Wirtz-Conklin:

Relevancia ambiental y económica en la enseñanza práctica de microbiologia

Recebido: 26/06/2021 | Revisado: 06/07/2021 | Aceito: 10/07/2021 | Publicado: 22/07/2021

\author{
Fabricio Ueda Reine \\ ORCID: https://orcid.org/0000-0002-0915-6672 \\ Universidade Estadual de Maringá, Brasil \\ E-mail: ra110687@uem.br \\ Lorena Aparecida Bianchi de Souza \\ ORCID: https://orcid.org/0000-0002-9611-5069 \\ Universidade Estadual de Maringá, Brasil \\ E-mail: ra110683@uem.br \\ Jéssica Lima de Menezes \\ ORCID: https://orcid.org/0000-0003-3036-3139 \\ Universidade Estadual de Maringá, Brasil \\ E-mail: eng.jessica.lima@gmail.com \\ Rosana Ferreira Carli Cangussu Gomes \\ ORCID: https://orcid.org/0000-0002-9786-6120 \\ Universidade Estadual de Maringá, Brasil \\ E-mail: rfcarli@uem.br
Aline Campos Reis de Souza ORCID: https://orcid.org/0000-0002-5196-0672 Universidade Estadual de Maringá, Brasil E-mail: campos.acrs@gmail.com Camila Alves Mota ORCID: https://orcid.org/0000-0001-7702-2812 Universidade Estadual de Maringá, Brasil E-mail: camilamota.am@gmail.com Benício Alves de Abreu Filho ORCID: https://orcid.org/0000-0002-3271-808X Universidade Estadual de Maringá, Brasil E-mail: baafilho@uem.br

\begin{abstract}
Resumo
As preparações coradas são os exames microscópicos mais comumente empregados em microbiologia, pois proporcionam uma melhor visualização dos microrganismos. Tendo em vista que as técnicas de coloração de Gram e Wirtz-Conklin são comumente utilizadas na rotina de laboratórios de microbiologia e nas aulas de microscopias coradas, este projeto teve como objetivo comparar a técnica padrão de coloração em superfície das lâminas, com a técnica por imersão, que por sua vez pode evitar o desperdício de corantes, impacto ambiental e diminuir custos laboratoriais e no ensino. Dessa forma, foram feitos esfregaços bacterianos (Escherichia coli; Staphylococcus aureus; Alicyclobacillus acidoterrestris e Bacillus subtilis) em lâmina, seguidos de fixação em chama. Após esse procedimento as lâminas foram submetidas à coloração pela técnica de superfície e pela técnica de imersão. Posteriormente as lâminas foram visualizadas em microscópio óptico comum e a resolução das imagens e características tintoriais foram avaliadas e registradas. A técnica de coloração por imersão, tanto para a coloração de Gram quanto para Wirtz-Conklin, evitou desperdício dos corantes utilizados nas técnicas, bem como, a saturação das soluções após muitas passagens de lâminas. Assim, a técnica de coloração por imersão é favorável para o uso nas aulas ou nos laboratórios de microbiologia. A aplicação dessa técnica mostrou resultados significativos para a diminuição do desperdício e, consequentemente, os impactos ao meio ambiente e à economia das instituições de ensino.
\end{abstract}

Palavras-chave: Coloração de Gram; Coloração de Wirtz-Conklin; Microrganismos; Microbiologia; Escherichia coli; Staphylococcus aureus; Alicyclobacillus acidoterrestris; Bacillus subtilis. 


\begin{abstract}
Stained preparations are the most commonly microscopic exam used in microbiology, as they provide a better view of microorganisms. Bearing in mind that Gram and Wirtz-Conklin staining techniques are commonly used in the routine of microbiology laboratories and in practical classes, this project aimed to compare the standard staining technique on slide surfaces, with the technique by immersion, which in turn can avoid waste of dyes, environmental impact and reduce laboratory and teaching costs. Thus, bacterial smears (Escherichia coli; Staphylococcus aureus; Alicyclobacillus acidoterrestris and Bacillus subtilis) were made on glass slides, followed by flame fixation. After, the slides were submitted to staining using the surface technique and the immersion technique. Subsequently, the slides were viewed under a standard optical microscope and the resolution of the images and tinting characteristics were evaluated and recorded. The staining by immersion, both for Gram stain and Wirtz-Conklin, avoided the waste of the dyes used in the techniques, as well as, the saturation of the solutions after many slide passes. Thus, the immersion staining technique is favorable for use in classes or microbiology laboratories. The application of this technique has shown significant results for the reduction of waste and, consequently, the impacts on the environment and the economy of educational institutions.
\end{abstract}

Keywords: Gram's stain; Wirtz-Conklin stain; Microorganisms; Microbiology; Escherichia coli; Staphylococcus aureus; Alicyclobacillus acidoterrestris; Bacillus subtilis.

\title{
Resumen
}

Las preparaciones teñidas son los exámenes microscópicos más utilizados en microbiología, ya que proporcionan una mejor visión de los microorganismos. Teniendo en cuenta que las técnicas de tinción de Gram y Wirtz-Conklin se utilizan comúnmente en la rutina de los laboratorios de microbiología y en las clases de microscopía teñida, este proyecto tuvo como objetivo comparar la técnica de tinción estándar en superficies de portaobjetos, con la técnica de inmersión, que a su vez puede evitar el desperdicio de tintes, el impacto ambiental y reducir los costos de laboratorio y enseñanza. Por lo tanto, se hicieron frotis bacterianos (Escherichia coli; Staphylococcus aureus; Alicyclobacillus acidoterrestris y Bacillus subtilis) en portaobjetos, seguidos de fijación con llama. Después de este procedimiento, los portaobjetos se sometieron a tinción mediante la técnica de superficie y la técnica de inmersión. Posteriormente, los portaobjetos se visualizaron bajo un microscopio óptico estándar y se evaluó y registró la resolución de las imágenes y las características de tinción. La técnica de tinción por inmersión, tanto para la tinción de Gram como para WirtzConklin, evitó el desperdicio de los colorantes utilizados en las técnicas, así como la saturación de las soluciones tras muchas pasadas de portaobjetos. Por tanto, la técnica de tinción por inmersión es favorable para su uso en clases o en laboratorios de microbiología. La aplicación de esta técnica ha mostrado resultados significativos para la reducción de residuos y, en consecuencia, los impactos sobre el medio ambiente y la economía de las instituciones educativas.

Palabras clave: Tinción de Gram; Tinción de Wirtz-Conklin; Microorganismos; Microbiología; Escherichia coli; Staphylococcus aureus; Alicyclobacillus acidoterrestris; Bacillus subtilis.

\section{Introdução}

A microbiologia engloba dois temas interligados: (1) a compreensão da natureza e do mundo microbiano, e (2) o uso dessa compreensão adquirida para produção de bens ou serviços, que possam aprimorar o desenvolvimento da humanidade e do planeta Terra. Microrganismos como as bactérias são classificados como seres vivos procariotos unicelulares, que têm como principal diferença entre gênero e espécie, sua forma, tamanho, e características celulares. Bactérias são livres de pigmentação, assim, para melhor visualizá-las, corantes orgânicos com afinidade específica por determinados compostos celulares podem ser utilizados a fim de aumentar o contraste de imagem em microscópio de campo claro (Madigan, Martinko, Bender, Buckley \& Stahl, 2016).

Com base nisso, vale lembrar que as aulas práticas de microbiologia são fundamentais para a construção do conhecimento científico do aluno, e no incentivo à sua criatividade. Castanho (2000) aponta que no Brasil há pouco espaço para o desenvolvimento de aulas práticas nas faculdades devido a limitação estrutural e financeira, que acabou dificultando o aprendizado prático nos laboratórios de microbiologia em instituições de ensino, este que ajuda os alunos a familiarizarem-se com os microrganismos, despertando ainda mais o interesse na área e colaborando na compreensão de conceitos (Castanho, 2000). Por tanto, faz-se necessário a abordagem de métodos alternativos de custo acessível na elaboração e realização de aulas práticas laboratoriais de microbiologia (Barbosa \& Barbosa, 2010).

Segundo Freitas \& Picoli (2007) a coloração de Gram é uma técnica diferencial muito utilizada na bacteriologia, com a finalidade de classificar microrganismos quanto a suas bases tintoriais, tamanho, forma e arranjo celular (Freitas \& Picoli, 2007). 
As bactérias coradas nessa técnica são divididas em dois grupos: bactérias Gram-positivas que coram em roxo pelo cristal violeta, pois possuem várias camadas de peptideoglicano e outros componentes não solúveis em álcool; e bactérias Gram-negativas se descoram com o álcool, que atua dissolvendo lipídios, o que contribui para permeabilidade da parede celular e posterior coloração em rosa pela fucsina. A diferença geral observada nas tonalidades existe por uma divergência nas propriedades físicas e químicas das paredes celulares bacterianas, tais como composição, espessura, densidade, porosidade e integridade (Moreira, Carvalho \& Frota, 2015).

Já a coloração de Wirtz-Conklin é empregada para visualizar esporos, uma estrutura espessa e muito resistente, que advém de situações críticas e adversas para o crescimento bacteriano. Os esporos são compostos por peptideoglicano que irá dar origem a uma parede vegetativa, envolvida pelo córtex. Devido à resistência apresentada pelos esporos, sua coloração demanda uma técnica que os submeta a alta temperatura, fazendo uso de verde malaquita e posteriormente da safranina para garantir um contraste na microscopia (Trento, 2018).

Para obter êxito na microscopia corada é preciso seguir corretamente o tempo de cada técnica e de cada corante individualmente. As técnicas de coloração para diferenciação de bactérias são amplamente utilizadas pela microbiologia, as variações conhecidas na metodologia dessas técnicas se tratam de alterações nas concentrações de corantes, troca de reagentes ou corantes em algumas técnicas, e modificações no tempo em que cada corante permanece sobre a lâmina. Alguns exemplos descritos na literatura são: modificação na técnica de Gram por Hucker e a modificação de Kopeloff (Isenberg, 1992).

Os corantes são amplamente utilizados por diferentes setores acadêmicos e industriais, descritos como compostos orgânicos solúveis, sobretudo em água, capazes de transferir sua pigmentação para outro meio a partir de suas afinidades químicas e físicas. Alguns corantes têm propriedades tóxicas, cancerígenas e recalcitrantes, capazes de causar danos profundos na biota aquática, impedindo a passagem total de luz, fotossíntese e oxigenação. Já para a saúde humana, podem causar o acúmulo anormal de metáfases, danos cromossômicos, entre outros fatores extensos de acordo com a formulação de cada corante. Por isso, existe uma preocupação em evitar o descarte irregular e até mesmo em diminuir o uso dos mesmos (Lellis, Polonio, Pamphile \& Polonio, 2019).

Visando a atual importância do desenvolvimento sustentável e preservação ambiental, as instituições de pesquisa e ensino devem criar metodologias alternativas para a economia de reagentes, além do descarte correto dos resíduos. É emergente que professores, alunos e técnicos se adaptem à novas técnicas de aprendizagem para o manejo eficiente de efluentes (Silva, Soares \& Afonso, 2010). Desta maneira, o objetivo deste estudo foi comparar as técnicas de coloração Gram e Wirtz-Conklin em superfície com a técnica proposta de imersão em uma perspectiva na diminuição de custos dos desperdícios e consequentemente menores impactos ao meio ambiente, bem como o tempo de saturação de cada reagente utilizado nas colorações dentro do suporte de lâminas.

\section{Metodologia}

Estudo desenvolvido no Laboratório de Microbiologia de Água, Ambiente e Alimentos, da Universidade Estadual de Maringá (UEM), Paraná, Brasil.

\subsection{Cultura dos microrganismos}

Cepas de microrganismos utilizadas no estudo: Escherichia coli (ATCC 25922), Staphylococcus aureus (ATCC 25923), Bacillus subtilis (ATCC 6633) e Alicyclobacillus acidoterrestris (CBMAI 0244T). Em meio Ágar Mueller-Hinton, com incubação a $35 \pm 0,5^{\circ} \mathrm{C}$ por 24 horas foi feita a semeadura para E. coli e S. aureus. Para B. subtilis, foi realizado o mesmo método, porém por 48 horas em incubação. E para A. acidoterrestris, foi realizada a semeadura em meio BAT, com incubação a $45^{\circ} \mathrm{C}$ por48 horas. 


\subsection{Coloração de Gram em superfície}

Esfregaços para as cepas E. coli e $S$. aureus foram coradas com cristal violeta (Êxodo Científica, Brasil) por 1 minuto, e posteriormente escorreu-se os resíduos do corante em um recipiente de descarte apropriado. Em seguida, as lâminas foram aplicadas com Lugol (Laborclin, Brasil) durante 1 minuto. Logo após, foi realizado o procedimento de lavagem nos esfregaços com água corrente de baixa pressão e partiram para a etapa de descoloração com álcool-cetona [Solução Descorante para Gram (Laborclin, Brasil)] (5-10 segundos). Novamente foi feito o processo de lavagem no esfregaço, e por fim cobriu-se com o corante fucsina (Dinâmica, Brasil) (30 segundos), lavados, e deixados secar espontaneamente (Cardoso et al., 2015).

\subsection{Coloração de Gram em imersão}

Conforme Cardoso et al. (2015), foi feita a coloração de Gram com algumas modificações. Após a confecção do esfregaço e fixação nas lâminas das cepas E. coli e $S$. aureus, as mesmas foram inseridas em um suporte para lâminas e mergulhadas separadamente em $20 \mathrm{ml}$ dos reagentes cristal violeta (por 1 minuto), lugol (por 1 minuto) e fucsina (10 segundos). Apenas a descoloração com álcool-cetona que foi feita pela técnica padrão de superfície devido a sua rápida saturação.

Respeitando as normas da UEM, coletou-se os resíduos produzidos durante o processo de coloração em um recipiente adequado para o descarte correto de efluentes.

\subsection{Coloração de Wirtz-Conklin em superfície}

Feita a confecção do esfregaço em uma lâmina para as cepas B. subtilis e A. acidoterrestris e deixar secar naturalmente ao ar, corou-se com solução aquosa de verde malaquita (Êxodo Científica, Brasil) a 5\% e aqueceu-se até a emissão de vapores por 5 minutos. Em seguida lavou-se a lâmina em água corrente de baixa pressão e o excesso do corante foi despejado em um recipiente de descarte. E por fim, as lâminas foram cobertas com solução aquosa de safranina (In Lab, Brasil) a 0,5\% durante 30 a 60 segundos, lavados, e deixados secar naturalmente ao ar (Cardoso et al., 2015).

\subsection{Coloração de Wirtz-Conklin em imersão}

Realizada as etapas de confecção e secagem do esfregaço para as cepas B. subtilis e A. acidoterrestris, a coloração de Wirtz-Conklin foi realizada conforme Cardoso et al. (2015) com algumas modificações. Em um suporte para lâminas contendo $20 \mathrm{ml}$ de solução aquosa de verde malaquita a $5 \%$ por 5 minutos em banho maria a $90{ }^{\circ} \mathrm{C}$ foram inseridas as lâminas contendo o esfregaço. Em seguida, o excesso do corante foi despejado em um recipiente de descarte apropriado e lavou-se a lâmina em água corrente de baixa pressão. Posteriormente, em um outro suporte para lâminas contendo $20 \mathrm{ml}$ do corante de contraste safranina a $0,5 \%$, foi inserida a lâmina contendo o esfregaço durante 45 segundos, e por fim, foi feito a etapa de lavagem com água corrente de baixa pressão coletando os resíduos em um recipiente.

Todas as lâminas coradas foram visualizadas em um microscópio óptico Olympus CX31 em lente de objetiva 100x.

\subsection{Descarte de resíduos}

Os resíduos dos corantes foram descartados em um recipiente e colocados em um local arejado para armazenar acúmulos de volume até ser transportado para um local específico fora da unidade geradora e edificação do estabelecimento. Frascos de até dois litros, resistentes, com tampa rosqueada, vedante e identificado com o nome e fórmula do produto químico, símbolo e expressão de resíduo químico tóxico foram utilizados como embalagens de descarte. E então, para o cumprimento da legislação do meio ambiente, foram encaminhadas em bombonas para o Programa de Gerenciamento de Resíduos Biológicos, Químicos e Radioativos (PRORESÍDUO). 


\subsection{Análise Descritiva}

Foi feita uma análise qualitativa com base nas propriedades e qualidades tintoriais em 200 lâminas, e análises quantitativas de acordo com as despesas obtidas no decorrer deste trabalho, assim como, as projeções de custos com relação a noções encontradas em UEM (2020). Ambas análises realizadas através do software Excel ${ }^{\circledR}$, classificando em cruzes. Sendo: $(+++)$ muito satisfatório, (++) satisfatório, (+) pouco satisfatório e (-) insatisfatório. E expressando os resultados em porcentagem $(\%)$, reais $(\mathrm{R} \$)$, mililitros ( $\mathrm{ml})$, unidade (un) e minutos (min).

\section{Resultados e Discussão}

Para a verificação da eficácia da metodologia proposta, foi realizada uma análise descritiva dos dados coletados na análise microscópica. Para tanto, a qualidade da coloração das lâminas foi classificada em (+++) muito satisfatório, (++) satisfatório, (+) pouco satisfatório e (-) insatisfatório (Figuras 1 e 2). É de suma importância ressaltar que os resultados (+) pouco satisfatório e (-) insatisfatório surgiram com a saturação dos corantes, ou seja, próximo ao fim das 40 lâminas utilizadas em cada teste realizado. Também observou-se que esfregaços feitos a partir de culturas antigas, ou lâminas coradas com esfregaços feitos a mais de 2 dias podem acarretar resultados errôneos na metodologia de imersão. Dessa maneira, é fundamental que o material utilizado seja novo, estéril e conservado. Segundo o Ministério da Saúde (1997), para manutenção e qualidade ideal, deve-se haver o repique bacteriano a cada 15 dias, o controle de pureza de cepas empregadas a cada 2 meses e lâminas preparadas a mais de 1 mês podem ser consideradas impróprias para uma análise coerente de morfologia e coloração.

Figura 1. Coloração de Wirtz-Conklin: A. B. subtilis +++; B. A. acidoterrestris ++; C. A. acidoterrestris +; D. B. subtilis -.

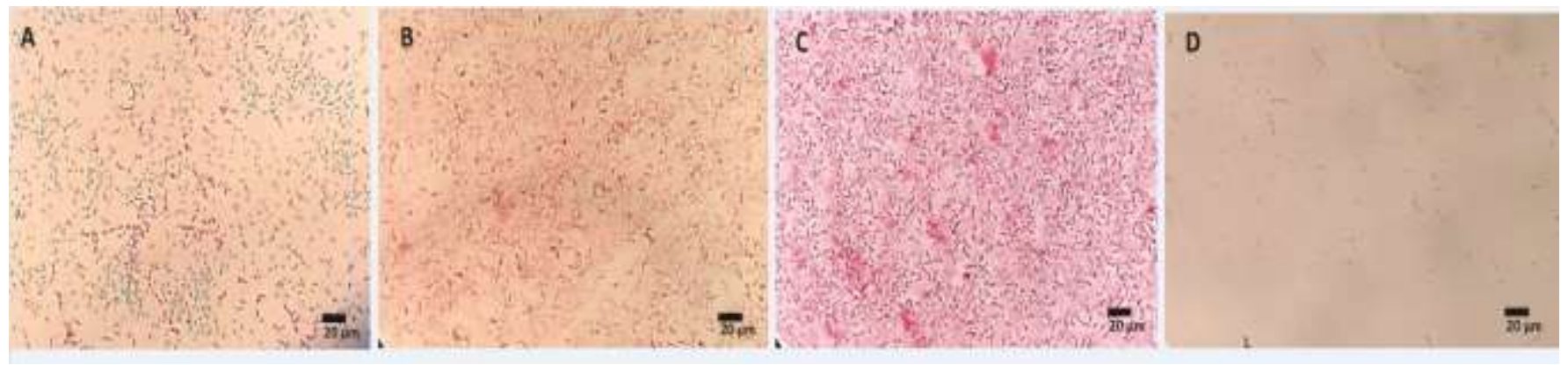

Fonte: Autores.

Figura 2. Coloração de Gram: A. Lâmina mista, S. aureus e E. coli+++; B. S. aureus++; C. S. aureus +; D. S. aureus -.

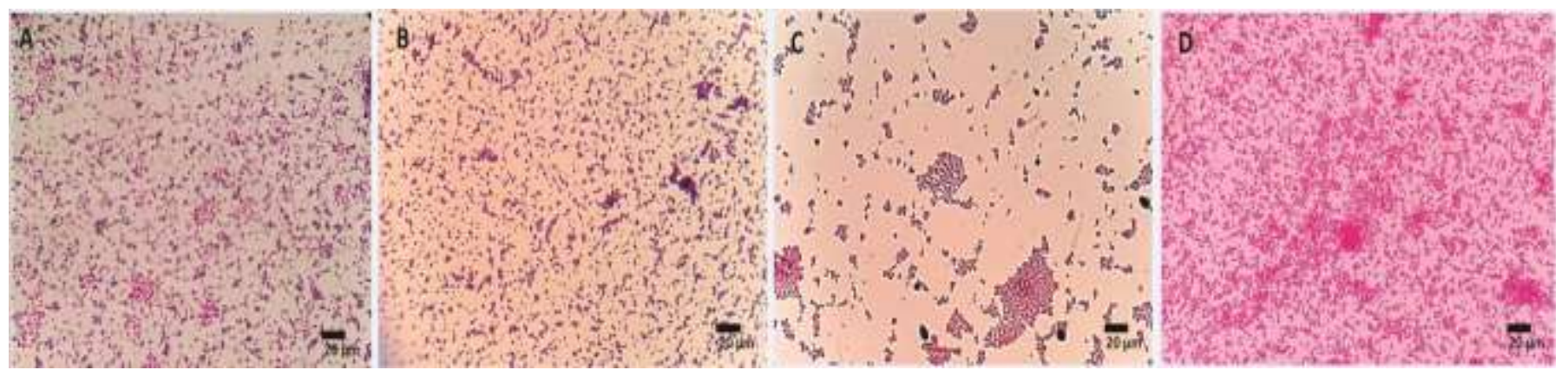

Fonte: Autores.

Corantes designados para Gram tem maior demanda nos laboratórios na Universidade Estadual de Maringá (UEM), sendo que, cristal violeta, fucsina, lugol e fenol cristalizado chegam a um uso de $3.000 \mathrm{ml}$ ao ano na metodologia tradicional por superfície (Tabela 3), corantes esses que contém propriedades químicas danosas, revalidando a importância dos resultados 
obtidos na Figura 3, onde aproximadamente 85\% das lâminas apresentaram resultados satisfatórios considerando a coloração de Wirtz-Conklin e, aproximadamente $95 \%$ das lâminas apresentaram resultados satisfatórios para a coloração de Gram. Isto significa que, de 120 lâminas analisadas utilizando o método de imersão para Wirtz-Conklin, 102 apontaram resultados conclusivos. De 80 lâminas analisadas utilizando o método de imersão para Gram, 76 apontaram resultados conclusivos.

Figura 3. Ilustração gráfica dos resultados obtidos na análise da qualidade das lâminas coradas por imersão.

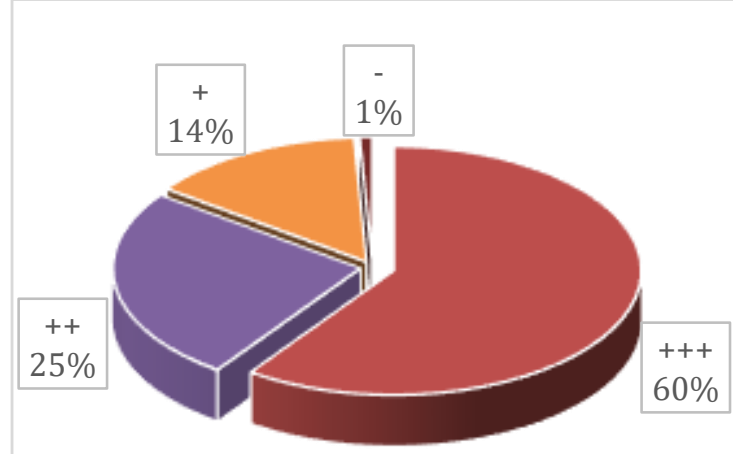

A.

$$
u+++++\quad+\mathbf{u}-
$$

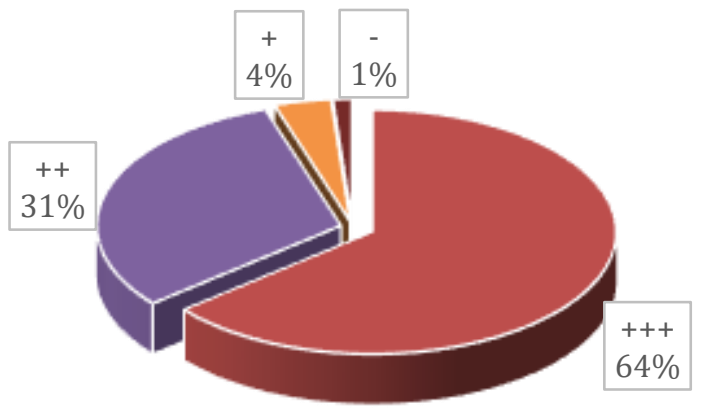

B.

$$
u+++\quad++\quad+\mathbf{m}-
$$

Gráfico A, representa a porcentagem obtida para cada categoria de classificação em cruzes, percentual a 120 lâminas, divididas em 3 testes de 40 lâminas cada, Wirtz-Conklin; Gráfico B, representa a porcentagem obtida para cada categoria de classificação em cruzes, percentual a 80 lâminas, divididas em 2 testes de 40 lâminas cada, Gram. Fonte: Dados da pesquisa.

Um dos corantes mais utilizados em laboratórios é o cristal violeta, membro do grupo catiônico dos trifenilmetano, tem propriedades recalcitrantes, que fazem com que persista no ambiente por um longo período. Pode causar envenenamento mitótico, promovendo anormalidade das metáfases, efeitos clastogênicos que induzem a danos cromossômicos, tumores em peixes, atrofia ovariana em ratos, cistite, insuficiência renal e respiratória e lesões oculares. Na água, pode diminuir a taxa fotossintética de plantas aquáticas devido a interrupção de passagem total de luz. No solo, pode inibir as taxas de fotossíntese, afetando a germinação de sementes e o crescimento das culturas (Mani \& Bharagava, 2016).

Nos resultados obtidos pela coloração de Wirtz-Conklin e a coloração de Gram por imersão (Tabelas 1 e 2), ambas foram eficientes para corar uma quantidade elevada de lâminas simultaneamente, somando mais êxito no quesito custo e quantidade de corantes utilizados em mililitro (ml) quando comparado a metodologia de superfície, uma melhora expressiva, já que segundo Chinelli et al. (2008), experimentos são considerados parte fundamental do aprendizado na área de microbiologia, no entanto as restrições financeiras pelas quais as instituições de ensino superior passam, torna difícil a aquisição de materiais e instrumentos adequados, responsáveis por resultados reprodutíveis e confiáveis. É possível constatar que para coloração de Wirtz-Conklin houve uma redução de $\mathrm{R} \$ 2,56$ para $\mathrm{R} \$ 0,82$ nos custos, resultando em uma economia de $68 \%$, e para coloração de Gram houve uma redução de $\mathrm{R} \$ 3,46$ para $\mathrm{R} \$ 0,85$, resultando em uma redução de 75\%, isto aplicado a 40 lâminas em cada metodologia de coloração. Já no tempo de realização de ambas as práticas, não houve uma disparidade de dados. 
Tabela 1. Volume de solução corante gasto, tempo e custo para realização da coloração de Wirtz-Conklin, empregando metodologia de superfície e imersão.

\begin{tabular}{cccccc}
\hline Metodologia & Lâminas (un) & VM (ml) & S (ml) & TT (min) & CT (R\$) \\
\hline Superfície & 01 & 02 & 02 & $05: 45$ & 0,06 \\
\hline Imersão & 01 & 20 & 50 & $05: 45$ & 0,82 \\
\hline Superfície & 40 & 80 & 80 & Variável & 2,56 \\
\hline Imersão & 40 & 20 & 50 & $72: 64$ & 0,82 \\
\hline
\end{tabular}

*VM: verde malaquita; S: safranina; TT: tempo total; CT: custo total. Fonte: Dados da pesquisa.

Tabela 2. Volume de solução corante gasto, tempo e custo para realização da coloração de Gram, empregando metodologia de superfície e imersão.

\begin{tabular}{ccccccc}
\hline Metodologia & Lâminas (un) & $\mathbf{C V}(\mathbf{m l})$ & $\mathbf{L}(\mathbf{m l})$ & $\mathbf{F}(\mathbf{m l})$ & TT (min) & CT (R\$) \\
\hline Superfície & 01 & 02 & 02 & 02 & $02: 40$ & 0,08 \\
\hline Imersão & 01 & 20 & 20 & 20 & $02: 18$ & 0,85 \\
\hline Superfície & 40 & 80 & 80 & 80 & Variável & 3,46 \\
\hline Imersão & 40 & 20 & 20 & 20 & $29: 05$ & 0,85 \\
\hline
\end{tabular}

*CV: cristal violeta; L: lugol; F: fucsina; TT: tempo total; CT: custo total. Fonte: Dados da pesquisa.

Segundo o Instituto Brasileiro de Geografia e Estatística (2016), de 2009 a 2014 o número de alunos matriculados em instituições públicas de ensino superior aumentou, devido a inclusão de métodos alternativos para ingresso universitário, como o Exame Nacional do Ensino Médio, vagas remanescentes, sobretudo, a elevação da alfabetização e escolaridade da população em geral. Nas estimativas constam que entre 2009 e 2014 houve um crescimento de aproximadamente $50 \%$ no número de brasileiros portadores de diplomas. Na Universidade Estadual de Maringá até 2019 existiam 442 laboratórios, 14.448 alunos de graduação matriculados, 70 cursos de graduação vigentes. Entre esses, dez cursos têm em sua grade curricular a matéria de microbiologia semestral ou anual (UEM, 2020).

Na disciplina de microbiologia básica ministrada na Universidade Estadual de Maringá, as duas técnicas de coloração são muito aplicadas para fins laboratoriais e acadêmicos. Estima-se que dez cursos tenham aulas de microbiologia, somando aproximadamente 440 alunos por ano (UEM, 2020). O montante de aulas práticas em microscopia corada aumenta a necessidade de reagentes, soluções corantes, e gastos para reproduzir a metodologia de superfície, como apresentado na Tabela 3. Mostrando o volume de corantes utilizados para a mesma quantidade de lâminas em técnica de coloração em superfície comparando com a técnica por imersão. Observou-se para cristal violeta, fucsina, lugol, verde malaquita e safranina uma diminuição de $75 \%$ na quantidade de corantes necessários para eficácia das colorações. Além da redução de gastos em material, os resíduos dos corantes foram coletados para serem descartados de acordo com as normas da Universidade Estadual de Maringá, evitando assim possíveis contaminações de efluentes municipais. 
Tabela 3. Dados aproximados de gastos anuais nas aulas de microbiologia da Universidade Estadual de Maringá.

\begin{tabular}{ccccc}
\hline & QUATS (ml) & VGATS (R\$) & QNTI (ml) & VGTI (R\$) \\
\hline CV & 3.000 & 15,00 & 750 & 3,75 \\
\hline FC & 3.000 & 300,00 & 750 & 75,00 \\
\hline Lugol & 3.000 & 66,00 & 3.000 & 66,00 \\
\hline Fucsina & 3.000 & 96,00 & 750 & 24,00 \\
\hline Descorante & 3.000 & 19,50 & 750 & 4,80 \\
\hline VM & 1.000 & 23,00 & 250 & 5,75 \\
\hline Safranina & 20 & 0,50 & 5 & 0,12 \\
\hline
\end{tabular}

*QUATS: Quantidade de solução corante utilizada ao ano pela técnica de superfície; VGATS: Valor gasto ao ano pela técnica de superfície; QNTI: Quantidade que seria necessária para a técnica de imersão; VGTI: Valor que seria gasto pela técnica de imersão; CV: Cristal Violeta; FC: Fenol Cristalizado; AE: Álcool Etílico; VM: Verde Malaquita. Fonte: Dados da pesquisa.

Uma pesquisa realizada em 2012, na região sul do Brasil, na área da bacia hidrográfica do Rio dos Sinos mostra que entre os 22 laboratórios registrados pelo Departamento de Informática do Sistema Único de Saúde do Brasil (DATASUS), 86,4\% deles utilizam fucsina, 59,1\% utilizam cristal violeta, 13,6\% utilizam lugol e 9,1\% utilizam verde malaquita. Quanto ao procedimento, $50 \%$ fazem o manuseio dentro de uma pia e 45,5\% utilizam bandeja para coletar os resíduos de corantes. Quanto ao descarte, 63,6\% descartam diretamente na pia, 31,8\% repassa os resíduos para uma empresa especializada e apenas 4,6\% fazem o tratamento dos resíduos (Allgayer, Raupp \& Cantarelli, 2015). Dependendo da forma de descarte, os corantes podem se alastrar no solo, sistemas alimentares e hídricos, através da água, essa que por sua vez é fonte vital para todos organismos (Telke, Kadan, \& Govindwar, 2014).

Em condições normais, os ambientes aquáticos são capazes de fazer autodepuração, ou seja, podem realizar autolimpeza dos resíduos que são descartados, isso decorre da presença de oxigênio dissolvido na água, da ordem de dez miligramas por litro, que promove a ação de bactérias na biorremediação. Mas a quantidade de elementos químicos descartados no meio diminui a taxa de potencial hidroxiliônico (pOH), tornando inviável a degradação natural dos elementos (Allgayer et al., 2015). A degradação dos corantes com propriedades recalcitrantes pode ser feita com aplicação de enzimas, basidiomicetos, métodos oxidativos avançados, $\mathrm{H}_{2} \mathrm{O}_{2}$ e luz UV. A aplicação conjunta de vários métodos é mais eficiente, podendo se obter uma degradação de cromóforos de 90-95\% (Nozu, Saldanha, Soares, Barbosa, Machado \& Silva, 2010).

Tais problemas socioambientais podem ser resolvidos com a relação paralela entre ciência, tecnologia e a comunidade, que através de medidas cooperadas podem mudar o preocupante cenário atual (Silva, Almeida, Nascimento \& Prudêncio, 2019). Com a difusão de conhecimento e criação de novas técnicas que aspirem a sustentabilidade, a ciência poderá contribuir diretamente para a melhoria do planeta, pensando a longo prazo, técnicas essas como a de imersão, desenvolvida por este trabalho.

\section{Conclusão}

Das lâminas testadas, $85 \%$ e $95 \%$ apresentaram resultados satisfatórios para coloração de Wirtz-Conklin e Gram 
respectivamente. Os resultados não satisfatórios se deram pela saturação dos corantes, ou seja, nas últimas lâminas imergidas. Em custos, a redução foi de 68\% para coloração de Wirtz-Conklin e 75\% para coloração de Gram. Assim, os resultados mostram que a metodologia de imersão é adequada para grandes quantidades de lâminas, podendo ser aplicado em pesquisas e desenvolvimento, mas também no aprendizado prático acadêmico, sendo uma metodologia de vantagens nos quesitos: custo, material, e especialmente, redução de impacto ambiental.

Para trabalhos futuros, pode-se avaliar afinco formas de degradação desses corantes, contando com enzimas, biorremediadores, fitorremediadores, métodos oxidativos, luz UV e $\mathrm{H}_{2} \mathrm{O}_{2}$. Uma vez que se faz necessário a aplicação de tais corantes, mas é indispensável compreender melhores formas de manuseio, como proposto neste trabalho, bem como, metodologias que minimizem e transformem resíduos.

\section{Referências}

Allgayer, N., Raupp, W. V., \& Cantarelli, V. V. (2015). Estudo avalia o descarte de corantes e meios de cultivo utilizados na microbiologia. Allgayer, N., Raupp, W. V., \& Cantarelli, V. V. (2015). Estudo avalia o descarte de corantes e meios de cultivo utilizados na microbiologia. https://www.labnetwork.com.br/noticias/descarte-de-corantes-e-meios-de-cultivo-utilizados-na-microbiologia/

Barbosa, F. H. F., \& Barbosa, L. P. J. L. (2010). Alternativas metodológicas em Microbiologia: viabilizando atividades práticas. Revista de Biologia e Ciências da Terra, 10(2), 134-143. https://www.redalyc.org/articulo.oa?id=50016922015

Cardoso, C. L., Nakamura, C. V., Dias Filho, B.P., Abreu Filho, B.A., Garcia, L.B., Ogatta, S.F.Y., \& Nakamura, T.U. (2015). Manual de Aulas Práticas. Universidade Estadual de Maringá.

Castanho, M. E. L. M. (2000). A criatividade na sala de aula universitária. In I.P.A Veiga \& M.E.L (Orgs) (.75-89). Campinas, SP: Papirus.

Chinelli, M. V., Pereira, G. R., \& Aguiar, L. E. V. (2008). Equipamentos interativos: uma contribuição dos centros e museus de ciências contemporâneos para a educação científica formal. Revista Brasileira de Ensino de Física, 30(4), 4505. https://doi: 10.1590/S1806-11172008000400014

Crubellate, J. M., Samed, M. M. A., \& Viudes, F. J. F. (2019). Base de dados 2019. http://www.cpr.uem.br/images/2019/pdf/BASE-DE-DADOS-2019-UEM.pdf

Elella, M. H. A., Sabaa, M. W., Elhafeez, E. A., \& Mohamed, R. R. (2019). Crystal violet dye removal using crosslinked grafted xanthan gum. International Journal of Biological Macromolecules, 137, 1086-1101. https://doi.org/10.1016/j.ijbiomac.2019.06.243

Freitas, V.R., \& Picoli, S. U. (2007). A Coloração de Gram e as Variações na sua Execução. Newslab, (82), 124-128. Retrieved from https://docs.ufpr.br/ microgeral/arquivos/pdf/pdf/Gram.pdf

Góes, M. C. C. (2013). Palha da carnaúba (Coperniciacerifera) como removedor dos corantes azul de metileno e cristal violeta. Dissertação de Mestrado. Programa de pós-graduação em Química da Universidade Federal do Maranhão, São Luís, MA, Brasil. https://tedebc.ufma.br/jspui/bitstream/tede/961/1/Dissertacao\%20Mauro.pdf

IBGE. Coordenação de População e Indicadores Sociais. (2016). Síntese de Indicadores sociais: uma análise das condições de vida da população brasileira. Instituto Brasileiro de Geografia e Estatística.

Isenberg, H. D. (1922). Clinical Microbiology Procedures Handbook. American Society for Microbiology (2. ed.).

Lellis, B., Polonio, C. Z. F., Pamphile, J. A., \& Polonio, J. C. (2019). Effects of textile dyes on health and the environment and bioremediation potential of living organisms. Biotechnology Research and Innovation, 3, 275-290. DOI: 10.1016/j.biori.2019.09.001

Madigan, M. T., Martinko J. M., Bender K. S., Buckley D. H., \& Stahl D. A (2016). Microbiologia de Brock (14. ed.). Artmed.

Mani, S., \& Bharagava, R. N. (2016). Exposure to Crystal Violet, Its Toxic, Genotoxic and Carcinogenic Effects on Environment and Its Degradation and Detoxification for Environmental Safety. Reviews of Environmental Contamination, 237, 71-104. DOI 10.1007/978-3-319-23573-8_4

Ministério da Saúde. (1997). Programa Nacional de Doenças Sexualmente Transmissíveis e AIDS: Técnica de Coloração de Gram. Telelab.

Moreira, J. L. B., Carvalho, C. B.M., \& Frota, C. C. (2015). Visualização bacteriana e colorações. Fortaleza, CE: Imprensa Universitária.

Nascimento, A. T. P., Dias, A. F., \& Santos, E. M. A. (2012). Tratamento anaeróbio de água residuária sintética têxtil contendo o corante verde malaquita. In Anais, 7 Congresso Norte Nordeste de Pesquisa e Inovação, CONNEPI.

Ribeiro, M. C., \& STELATO, M. M. (2011). Microbiologia Prática: Aplicações de Aprendizagem de Microbiologia Básica Bactérias (2. ed.). Editora Atheneu.

Silva, A. F., Soares, T. R. S., \& Afonso, J. C. (2010). Gestão de Resíduos de Laboratório: Uma Abordagem para o Ensino Médio. Química Nova na Escola, 32(1), 37-41. Retrieved from http://qnesc.sbq.org.br/online/qnesc32_1/08-PE-9208.pdf

Silva, R. L., Almeida, E. dos S., Nascimento, E. S. do, \& Prudêncio, C. A. V. (2019). Professores de Química em Formação Inicial: o que Pensam e Dizem sobre as Relações entre Meio Ambiente, Ciência, Tecnologia e Sociedade. Revista Brasileira de Pesquisa em Educação Em Ciências, 19, 537-563. doi: 10.28976/19842686rbpec2019u537563 
Research, Society and Development, v. 10, n. 9, e9510917585, 2021

(CC BY 4.0) | ISSN 2525-3409 | DOI: http://dx.doi.org/10.33448/rsd-v10i9.17585

Telke, A. A., Kadam, A. A., \& Govindwar, S. P. (2014). Bacterial Enzymes and Their Role in Descolorization of Azo Dyes. Microbial Degradation of Synthetic Dyes in Wastewater. DOI: 10.1007/978-3-319-10942-8_7

Trento, A. (2018). Colorações usadas em microbiologia. (Monografia). Especialização em Microbiologia Clínica da Academia de Ciência e Tecnologia. http://www.ciencianews.com.br/arquivos/ACET/IMAGENS/Artigos_cientificos/3-Coloracao_microbiologia.pdf 